\title{
Specificity of Web User Interface (WUI) Organization in Different Cultures
}

\author{
Julia Taratukhina ${ }^{1}$, Dmitry Aldunin ${ }^{2, *}$ \\ ${ }^{1}$ Department of Innovation and Business in Information Technologies, National Research University Higher School of Economics \\ Moscow, Russia \\ ${ }^{2}$ National Research University Higher School of Economics Moscow, Russia \\ *Corresponding Author: D_Aldunin@mail.ru
}

Copyright (C) 2013 Horizon Research Publishing All rights reserved.

\begin{abstract}
Nowadays, the Internet has become the main medium of information exchange. It affects such areas as business, entertainment, advertising, e-education, mass media, various communities of interest and so on. Very often, such e-resources involve multicultural audience. There are different approaches to creation of ergonomic user interface design in different cultures, though. This particular paper is devoted to analysis of differentiation of those approaches and is also aimed at working out a list of recommendations on the ways to improve ergonomic user interface design of e-resources for multicultural audience.
\end{abstract}

Keywords Ergonomic Semiotics, Web User Interface (WUI) Design, Ergonomic Design, Multicultural Audience, Cognitive Specificity

\section{Introductory Part}

\subsection{Statement of Problem and Evaluation of the Relevance of Chosen Data Domain}

The given research aims at analysing and evaluating the necessity to differentiate user interfaces on the web for various culture groups, as well as at producing recommendations for improving the ergonomics of the web resources targeting multicultural audience.

Nowadays, cross-cultural problem is one of the basic things to consider when creating e- resource focused on different cultures. Since the advent of using information technology for delivery of information, new tools and methods to present it have occurred. Some of them both partly decrease and increase psychological tension of the process of acquiring knowledge. According to G. Uzilevsky [5], ergonomic semiotics is a scientific practice, which studies the problems common to semiotics, linguistics and ergonomics, and is able to resolve a number of problems associated with the need to make information intelligible to the target audience, depending on the cognitive specificity caused by cultural differences. In the era of worldwide Internet's intromission to most of areas of life, the study of cross-cultural aspects of ergonomic semiotics is the most important.

The design of on-line resources certainly embodies national culture of its creators. User web interface must meet the cultural and pragmatic expectations of the user (especially in navigation, graphics and content) for maximum efficiency of presenting information. For example, it is possible to observe that the design of European sites is characterized by ease of navigation, logic and predictability, dosage of information and no hidden content.

The paper aims at describing the specifics of organizing the user interfaces in different cultures and at providing practical recommendations for developing culture-sensitive interfaces.

The object of the research is the culture groups of the Web resource target audience. The subject of the research is a possibility of grouping them in order to determine the number of the site interface options required and to predict the degree of dissatisfaction with the site interface for different culture groups of the target audience.

Pragmatic factors must necessarily be taken into account during the process of creating and monitoring resources aimed at multicultural audience. There are different cognitive models of perception and processing of information in the eastern (collectivist and inclined to dialectic) cultures and the western (individualistic and inclined to formal logic) cultures. In the West, the information is mostly directly perceived through the prism of person's individual perception and is superimposed on the existing information background. In the East, users simply collect information without personal critical reflection during the consumption of the information content.

On this basis, determination of the nature of user interface and establishment of the principles of development of efficient and convenient sign vehicles to communicate with different types of software and hardware should be included to the purposes of ergonomic semiotics. For this investigation, cross-cultural context for the user interface 
development will be the object of the most interest, because of the need to adapt information for cognitive specificity of different cultures. In the above-mentioned context, ergonomic semiotics offers the following research areas:

- Identifying and examining approaches to creation and usage of user interface as an interactive multi-level system in different cultures;

- Color code in different cultures;

- Iconic language in different cultures;

- Music code in different cultures;

- Specific parameters of users' behavior on the sites due to the specifics of thinking and acting in different cultural groups.

Theoretical and methodological framework for this study is the following: the works of Geert Hofstede on cultural dimensions, Aaron Marcus' works on the culture-sensitive interfaces development, statistical research in the field of conversion conducted by Forrester Research Inc. and Listrak agencies, research in the field of the Russian Internet users network activity conducted by TNS and a number of other studies mentioned as the reference. The empirical basis of the research is the information about cultural dimensions of 110 countries from the work "Cultures and Organizations 3rd edition 2010" (by Geert Hofstede), the results of the online survey in the anonymous multicultural internet-community 4chan.org/int and data of the authorial insider's view.

\subsection{User Interface from the Point of View of Ergonomic Semiotics}

The user interface in the context of ergonomic semiotics can be defined as a multi-level interactive information system, consisting of a natural language, iconic language, and color and music codes. The term "user-friendly" can be considered applicable to the pragmatic aspect with the convenient presentation of verbal and iconic segments. In different cultures, differentiation of the forenamed parameters will be noticeable. When talking about ergonomic semiotics' requirements and evaluation of user interface, it is appropriate to differentiate them in:

-Pragmatic requirements include ease of learning, ease of intussusception and usage of information that improve the efficiency of the user activity, etc. In particular context of these requirements, during the further examination of various aspects of the design of user interfaces the cultural specificity of users will be taken into account. From the perspective of pragmatics user interface should match the cognitive, psychomotor, emotional, motivational characteristics of the users, as well as comply to their needs and objectives;

-Semantic requirements: resistance to semantic errors, backbone connections, availability of feedback on the performance of the user. From the standpoint of semantics, interface should meet the standards of any domain of knowledge with the maximum regard to the users' subject language;
-Syntactic requirements: flexibility, freedom to choose the means of information retrieval and the realization of these relations in a particular information system;

-Sigmatic requirements: the relationship between the object, its thinking reflection and signs which represent this reflection; in other words, the logical connections and meanings;

Thus, multicultural context assign the following main tasks, which should be solved in the future work:

1. Defining the criteria of the user interface's suitability for representatives of different cultures;

2. Description of the conformity of functional and graphical features of interface specificity to different cultures users' cognitive specificity, in order to avoid possible frustrations, mistakes, and slowing tasks solving; 3. Description of the basic principles of national media cultures.

\section{The History of Research}

Exploring cultural differences, R. Nisbett [8] identified several factors, which vary depending on the cultural affiliation and have influence on the behavior of individuals: "attention to the field" dominates in the East, and "attention to the main objects" - in the West. Nisbett carried out a series of experiments with American and Japanese users, which showed that the Japanese were paying attention to the features of the surrounding background about $70 \%$ more often than Americans were, even though they both were equally likely to mention the details of main content. In addition, Japanese almost twice as often noted uncertain linkages and relationships with the environment. Nisbett saw the roots of these differences in the cognitive-semiotic mechanisms inherited from either holistic (ancient Chinese) or from the analytic (ancient Greek) system of understanding the world.

Moreover, relying upon G. Hofstede's studies [9], it is possible to conclude that Asians are more liable to perceive the whole picture almost without using the division into categories and formal logic. They rely on the dialectical and empirical aspects. At the same time, Europeans prefer strict cataloging and formal structure.

According to M. Kholodnaya's research [6], cognitive style reflects the way of perceiving, analyzing, structuring and categorization of the world, the style of learning. "High cognitive complexity" dominates in most Western cultures that means a multi-dimensional model of reality in a variety of relationships. While Eastern cultures are characterized by "low cognitive complexity" - unique, simplified interpretation of reality.

All of this specificity should be somehow reflected on the user interaction with e-resources, and understanding of it will help to adapt e-resources to socio-cultural preferences of users. Developers, who have to deal with users of different cultural groups, of course, should consider the above-mentioned features. First of all, the following should 
be taken into account when structuring and cataloging information: the representatives of Western cultures often requires detailed information on a specific aspect, whereas representatives of Asian cultures will probably want to explore a question in common.

Initially it was assumed that the factor uniting user and interface is information. Now it is widely thought that it is activity [4]. It seems to us that both factors have a place to be: working with information and forming ideas about the subject should be considered as a strategic activity, while the interaction with the interface aimed at obtaining this information - as a tactical activity. It is possible to define activity as a set of actions, which ensure meeting the goal. It can be assumed that in different cultures the structures of acting differ by the spatio-temporal characteristics. Following the classification of R. Lewis [7], the specificity of the different cultures can be classified in monoactive, poliactive and reactive styles.

\section{Using the Template}

Interface creation and design in a pragmatic way can be reflected with a "model of the world" metaphor. Therefore, the main task of interface ergonomic design modeling and preparing content for e-resource is analyzing the following criteria for the construction of a model:

- Consideration of the relationship of thinking and acting specificity activity and choice of user interface elements in the sense of cultural specificity;

-The type and content of information (cultural-specific parameters);

- The structure and sequence of the elements positioning on the screen, the number and detail of elements in the field of perception (pragmatic specificity);

- Semantic analysis of expressions and professional terminology - instructions, tips, names of system elements and their pragmatic adequateness;

- Techniques of nonverbal coding as icons, signals, colored images;

- Presence of adequate feedback.

In other words, general design-typographic aspects of the text, which are the most appropriate for the perception of textual information by the user.

All requirements submitted for ergonomic e-resource interface organization can be divided into four main categories:

- Navigation;

- Architectonics and structure of the page;

- Ability of getting feedback, access, updating content, the dominant style of representation of information;

- Color and font decision;

\section{Practical Analysis and Finding out Correlations between Existing Theoretical Information and Real}

\section{Websites Appearance: Criterions and Examples}

Turning to practice, it is possible to see that the design of user interfaces in different countries demonstrates cultural differences in set of colors, degree of assistance in navigation, information-intensity, extent of its grouping, etc. It is possible to identify a number of the most important parameters for further analysis of websites.

The first and foremost are iconic symbols. There will be complexity in matching one-to-one relation between specific concepts and iconic symbols in different cognitive contexts. Accordingly, creation of user-friendly interface designed for multicultural audience requires professionalism in designing iconic signs, because of the need to analyze the subject area and the cultural characteristics of the target audience and determine the composition and features of iconic signs.

The second class of problems in iconic is associated with a representation of abstract concepts as objects, expressed by iconic signs or represented in the form of visual metaphors. Depiction of abstract concepts in different cultures, differentiation within the iconic symbols, figural objects, pictograms indicating the nature of performing action, pictograms used as functional analogue and denoting the result of the performed steps should be considered.

As it is well known, the basic functions of iconic signs include:

-notation of similarity to a particular object;

-replacement or representation of an object;

- illustrative and communicative function.

According to observations, high-context cultures' websites contain more pictures and less text than sites of low context cultures. However, it is clear enough that the images (signs, icons) may be perceived in quite a different way in different cultures. For example, Arab resources show many national and religious symbols regardless of the topic. National symbols are in a very active use in Japanese resources. Not all of the iconic signs that are easily understandable to representatives of Western cultures can be adequately understood in the cultures of the East. And, accordingly, vice versa. As more as possible neutral symbols should be used to avoid pragmatic inconsistencies when dealing with multicultural audience.

As for set of colors, first of all, it is very important to consider the principle of functional, physiological and emotional relevance, and only then the factor of cultural specificity. It can be noted that in most European e-resources used gray and brown hues, while in Asian e-resources dominates hues of red. However, the symbolism of the color can be interpreted ambiguous too.

From the standpoint of navigation parameters menu layout, interface objects used and the place of the text in the site's space are important in the chosen context. For example, Arabic and Israeli text is read from right to left, you can still meet the vertical inscriptions or entire articles in Japanese and Chinese. Parameters of access to pages and 
information also may have significant importance. In some cultures, users usually must have the permission to see certain information, while in other cultures information is mostly publicly available. In addition, there are differences in the interaction with users: errors and instructions for navigation can be placed in a rude form, while they may be accompanied by polite comments explaining why something possibly went wrong, and providing instructions on how to fix it. As for the menu, the Russian and Asian e-resources usually have vertical menu, while Western one - horizontal. It is connected to the construction of site, for example, the majority of American resources occupy the entire width of the page, while in the Arab sites there is the "top-down" structure.

Specificity of filling the site with content can also be differentiated according to cultural factors. In cultures with a high index of individualism, for example, for most of the web resources the method of open content is used that means users are able to add and edit the information placed, which is not typical for collectivist cultures. E-resources of individualistic cultures are usually characterized by ease of presentation, clarity of metaphors, navigation menu organized to prevent the user from getting lost, etc.

Comparing the design of sites of different cultures, it can also be seen that, for example, Asians prefer "pop-ups", which are very rarely seen on the resources of northern Europe. Chinese websites often contain several simultaneous animations, overlays, sliders. This can be explained mostly by the fact that the pop-ups do not appear immediately but after some time. This is unusual for low context Western cultures because of being annoying and distracting for their representatives, and, on the contrary, is positively perceived by Asian users.

It has been observed that the representatives of Asian cultures do not like to type text; they prefer to click on the links, so their sites are often overloaded with links, images, and other interface elements, which allow avoiding typing. Such a variety of elements often shocks representatives of low context cultures.

There is one more type of differences between cultures they pay attention to different objects in the website considering the different types of information to be important. Moreover, according to D. Matsumoto [3], people from various cultural groups may use different strategies for working with information. For example, there is a tendency to make decisions based on the representativity in cultures with high level of such Hofstede's cultural dimension as uncertainty avoidance. This trend is affects user interaction with the interface too. That means that graphical applications in the form of presentations, models, etc. are needed in addition to the text information. Representatives of high context cultures often prefer descriptions to the facts, while the inhabitants of the countries with a high index of uncertainty avoidance tend to get detailed information. So that variety of sources of information should be offered on the international e-resource: descriptive text, statistics, pictures, videos (of different styles), etc.

After all, according to research of R. Zaltsman [2], in a present-day cross-cultural information space there is a tendency of transferring Western web culture to the web space of the East, and the eastern web culture largely begins to adapt to the western.

\section{Working-out Practical Recommendations and Decisions}

Focusing on the specificity of the page structure and font decisions, it is interesting to notice the following difference: in English texts the so-called ragged right formatting is used, that means that the text is aligned to the left and the right edge is "torn". Paragraphs of text are separated by vertical indentation. In Russia, a traditional text layout is aligned to the column width and the separation of paragraphs is more commonly known as a "red line".

Developers of interface for multicultural e-resource must take into account the consequences of changing the standard date, time, currency, and other service information to local. For example, in the U.S.A. dates are traditionally displayed in the format YYYY/MM/DD or MM/DD/YYYY, while most European countries adopted representation DD/MM/YYYY. Thus, date format could cause confusion, especially when the number of months is less than 12 $\left(12 / 04 / 2012\right.$ can mean both $12^{\text {th }}$ of April and $4^{\text {th }}$ of December). There also should be used the encoding and fonts that allow the usage of local currency symbols $(£, \$, ¥$, $€$ and more specific, such as $\mathbf{P}$ ).

Using specific characters for different countries can be greatly facilitated by the use of CSS3: previously web designers had to use only the most common fonts, and labels with a rare signs had to be replaced with the image, but now it is possible to load the native fonts for web document. Moreover, for sure, the days when users had to install the fonts themselves to properly use the e-resource are far ago.

The use of modern web technologies such as CSS3 and HTML5, offers great opportunities for the practical implementation of the recommendations for the creation of ergonomic culture-oriented design. In the continuation of the study the summary table of relations between numerical Hofstede's metrics and exact ways to present the content as well as the need for a specific user interface elements will be formed.

For cultural groups differentiation, Geert Horstrede's dimensions of national culture were chosen, which are: Power Distance, Individualism versus collectivism, Masculinity versus femininity, Uncertainty avoidance, Long-term versus short-term orientation, Indulgence versus Restraint.

In the part of recommendations for web-based user interface organization, the research refers to educational materials of UC Santa Cruz «HCI Foundations: Individual Differences», which are based on the paper «Globalization of User-Interface Design for the Web», published in 1999 by 
Aaron Marcus with his co-authors John Hermitage and Walker Frank, and also on its continuation «Cultural Dimensions and Global Web Design: What? So What? Now What?».

Practical recommendations were drown up in accordance with the following web-design characteristics chosen by Marcus, which are influenced by cultural specificity:

Metaphors - notable for images used in site design;

Mental models - models of thought train from real life, which are stimulated while using the site;

Navigation - ways of moving inside the web pages or from one page to another;

Interaction is the specifics of interaction between the user and the interface.

Appearance is features of the site design, such as color scheme, forms, layout, sounds, video etc.

The major problems in using these data were that Marcus considered only the extreme parameters of Hofstede's dimensions, or, in other words, his recommendations suited only target audiences with extremely high or extremely low parameters of Hofstede's cultural dimensions. Furthermore, these recommendations were formulated when the Internet was only beginning to be used commonly and long before Web 2.0 appeared. For this reason, these recommendations have been noticeably worked over so as to bring them up-to-date. Then, the intermediate parameters of Hofstede's dimensions recommendations have been added.

Among the targets of the research was to test the possibility of distinguishing certain groups within the target audience, which could be offered one interface variant with minimal discomfort while using the interface. To solve this problem, the data were clustered based on the basis of the $\mathrm{k}$-means statistical method. This method is based on splitting the set of vector space elements into a predetermined number of clusters $\mathrm{k}$.

Various divisions into clusters have been used with the number of clusters $\geq 3$. We have found out that 3 is the optimal number of clusters when using the method "Intelligent Choice of the Number of Clusters in K-Means Clustering", and a bigger number of clusters does not cause the better correspondence between the clusters and the real-life distribution. For instance, there appear borders between clusters at the levels of Hofstede's dimensions characteristical for many countries. In other words, representatives of many nearly identical groups could see the different variants of the interface, which contradicts the logics. While dividing every Hofstede's dimension into three clusters, the users see the least differences in their interface.

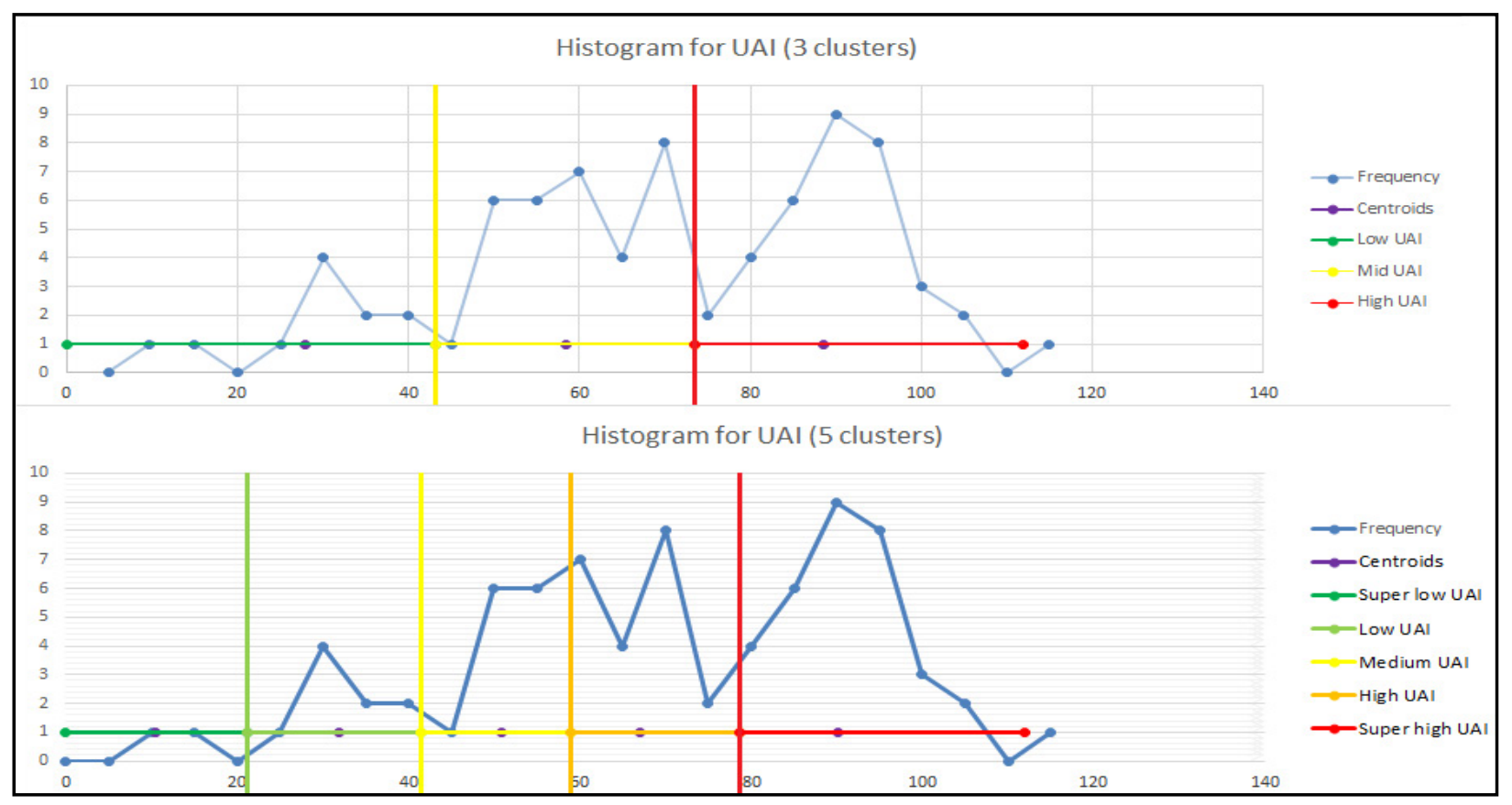

Figure 1. Comparing the division into 3 and 5 clusters based on the bar graph "Avoiding indefiniteness"

We conducted a survey in the multicultural anonymous online community boards.4chan.org/int/ where we polled 
representatives of 17 countries in order to find out the specific features of the user interface in their countries.

The poll was carried out in the form of delayed communication: a new thread was started in the community asking its users to participate in the poll, and the following questions were placed there, which were worded in informal English:

1. Where are you from? Were you born there?

2. What are the features of websites in your country? (color, text layout, menu structure, the ratio between images and text - whatever you find interesting);

3. Give a few examples of typical websites from your country or commonwealth.

Here is the alphabetical list of countries whose representatives took part in the poll:, Argentina, Canada, England, France, Germany, Holland, Hungary Ireland, Norway, Paraguay, Philippines, Poland, Spain, Sweden, Switzerland, Turkey, USA.

It should be mentioned that the poll was carried out in a completely anonymous way, no information about the aims of the poll was provided, no information about the respondents (whether personal data or IP-address) was received and stored.

On the basis of the obtained data for each of the three intermediate levels received through the application of k-means clustering method in each of the six Hofstede's dimensions, practical recommendations have been formulated on the design of the website interface, as well as on the specifics of the interfaces listed above.

For further approbation and verification of the produced recommendations on developing the ergonomic design of culture-sensitive interfaces, an ASP.NET application was developed, which allows to poll various groups on the basis of the produced recommendations and receive feedback on them being true or false.

The application collects the data from the stored recommendation file (for each of the 3 levels of the 6 Hofstede's culture dimensions), and constructs a 6-dimensional hypercube with $3^{6}=729$ apexes, i.e. sets of recommendations for various culture groups. When learning about the nature of the poll, a respondent may choose their country from the given list, or type the values of the Hofstede's parameters, if a respondent is polled after the testing.

Curve graphs have been drawn, reflecting the growth of dissatisfaction the farther from the cluster centroid the Hofstede's dimension marks are. Also, a hypothesis has been formulated of the necessity of identifying the target group's preferable values of Hofstede dimensions and forming the clusters on their basis in order to reduce the cost of the development, and of the necessity to move clusters against their statistically calculated positions, and to identify the levels of tolerable dissatisfaction, which does not demand changes to the design.

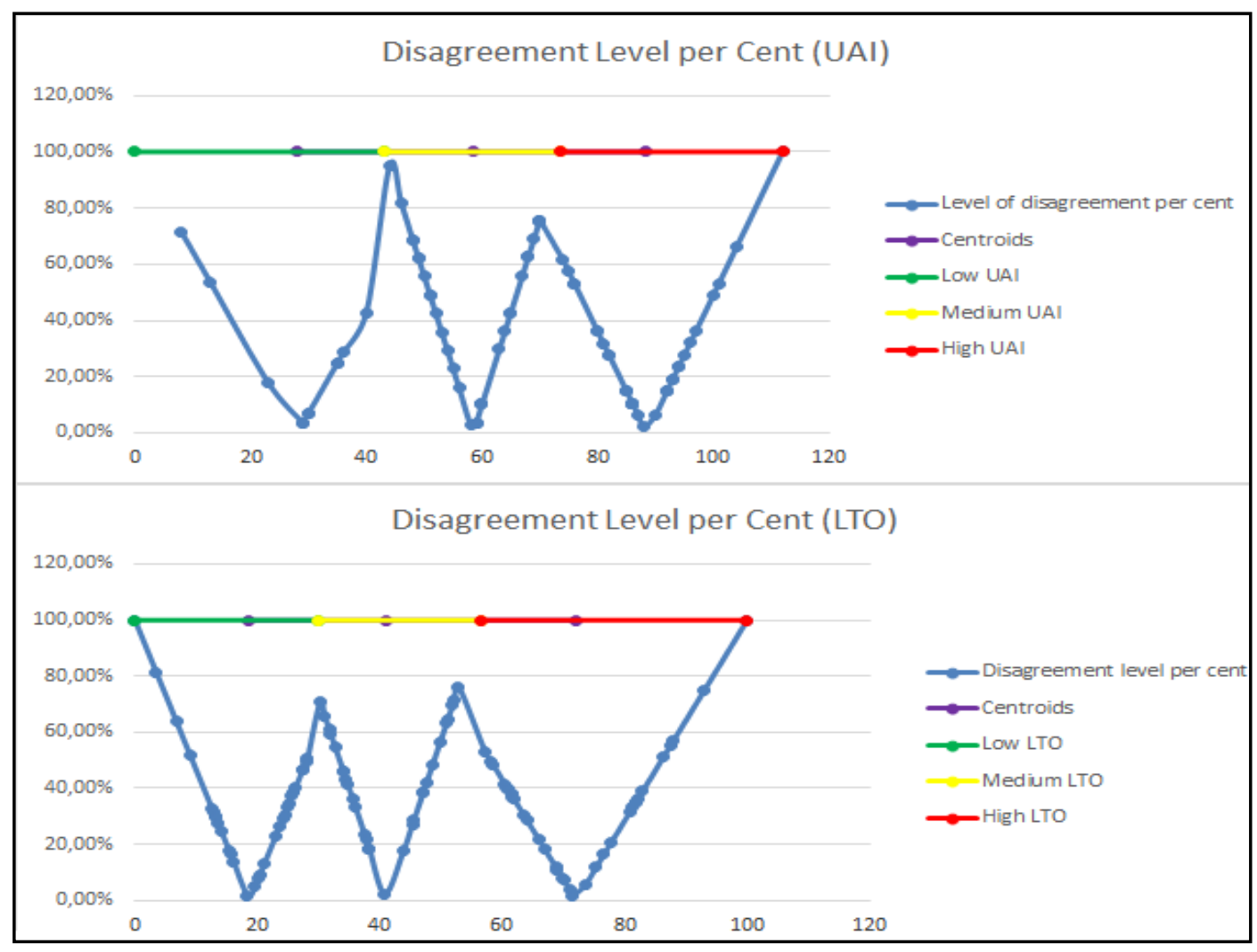

Figure 2. Percentage ratio between the value of Hofstede's dimension marks distance to the cluster's centroid and distance form the cluster's centroid to the farther border of the cluster; two Hofstede's dimensions are illustrated.

The developed ASP.NET application is available at www.liti.somee.com/v0_8 and is used to poll people in 
multicultural Internet communities. The results of these surveys will allow to iteratively adjust the practical recommendations on the development of culture-sensitive interfaces. Besides, this allows to compare the received interface disagreement levels with the real percentage of the negative feedback, which will help verify the formulated hypothesis and allow to rely on the received data and deem them verified.

\section{Conclusion}

Thus, it can be said without prejudice that that the practical principles of ergonomic design of e-resources should be supported by approaches, developed in the field of semiotics, cultural studies, psychology, which identify rules of combination of the text, images, semantics, fonts, ways of emphasizing text components and its perception. Moreover, one of the important components that need to be considered is specific ways of context perception in different cultures and socio-cultural approach to the creation of e-resources' design, as well as specific of acting and work with information.

This research will be the beginning of series of works devoted to the analysis of conformity of cultural specificity of target audience and the design features needed to ensure maximum comfort and ease of web user interface designed for this audience. The end result of the entire work will be the development of software environment that facilitates the development of sensitive to the culture interfaces.

\section{Further Research}

Hofstede's dimensions of estimating national identity are not precise and accurate enough; furthermore, they cannot be applied to identifying groups within the target audience of a website oriented for one country. Thus, the necessity to develop a range of tests, which will provide a more precise differentiation into culture groups according to Hofstede's dimensions. As mentioned before, the evaluation can be made only by one or two Hofstede's parameters which are found essential for a certain situation (depending on the specifics of the company's activities and the target audience). Methods of finding such parameters are yet to be developed and verified.

The achieved results can be of use not only for web design firms and usability analysts, but for any company involved in e-commerce whose target group can be split into several culture groups, as well as for lecturers reading a course in Cross-cultural communication and Ergonomic user interface design.

The achieved results deemed relevant, as it is essential nowadays when designing a site to take into account the cultural parameters of the target group. One of the reasons for this is a rapidly growing number of cross-border purchased (in Russia e-commerce grew 50\% in 2012).
Besides, now many companies have already come to understand the concept of Design Ladder, describing 4 stages of company's maturity in the issues of usability and design: from "no design" when the preferences of the end user are not taken into account, to "design as strategy" when developing and updating the design becomes part of the company's aims and plays an important part at every stage of development.

An important positive effect of applying the achieved results is that the given research will allow to clean up the conversion funnel of the buyer's carts abandoned due to disagreeable interface. For further understanding the positive effect, one must bear in mind the following fact: in June 2012 ComScore polled 3000 American on-line buyers and found out that $57 \%$ of users do not complete the purchase as they visit the site only to see the goods, compare the prices, read the reviews. These people initially do not plan to purchase anything, however they are also very important as they show their interest for certain goods.

\section{REFERENCES}

[1] Ageev V. Semiotika, M. Vesj mir, 2002 - 253 p.

[2] Zaltsman R. Transnationalnoe distancionnoe obrazovanie: Kooperatsyja I (ili) konkurentsyja? Mezhdunarodnaya konferentsyja "Infornatsyonno-telekommunikatsyonnye tekhnologii v obrazovanii” - 2003, Moscow № 6. 149-153 pp.("Transnational distance education: cooperation and (or) competition? International conference "Information-telecommunication technologies in education")

[3] Matsumoto D. Psikhologiya I kultura. Sovremennyje issledovaniya. SPb.:Praym-Yevroznak, 2002. (Psychology and culture. Modern researches)

[4] Sugak E. Ergonomicheskie aspekty proyektirovaniya poljzovateljskogo interfeysa // Avtoreferat dissertatsii na soiskanie uchenoy stepeni kandidata psikhologicheskikh nauk. M. MGU 2011

(Ergonomic aspects of designing user interface // abstract of the dissertation paper for obtaining $\mathrm{PhD}$ in psychology. M. MGU 2011)

[5] Uzilovskiy G.Y. Nachala ergonomicheskoy semiotiki. - Orel: ORAGS, 2000. - 408 p. (The beginnings of ergonomic semiotics)

[6] Kholodnaya M.A. Kognitivniye stili. O prirode individualnogo uma. 2-izd. - SPb.: Piter, 2004. - 384 p.

(Cognitive styles. On the nature of individual mind. 2nd edition)

[7] Lewis R. (1996) When Cultures Collide. Managing successfully across cultures. London.

[8] Nisbett Richard (2003) E. The Geography of Thought. Free Press. 
[9] Hofstede G. (1980) Culture's Consequences, International Differences in Work Related Values. Sage Publications - 328 p. 